\title{
Rumo a uma teoria da midiatização: exercício conceitual e metodológico de sistematização
}

\section{Luís Mauro Sá Martino}

Doutor em Ciências Sociais pela PUC-SP, Brasil. Professor do PPG em Comunicação da Faculdade Cásper Líbero. Imsamartino@gmail.com

\begin{abstract}
Resumo
O conceito de midiatização tem sido empregado de maneira crescente nos estudos de Comunicação nas últimas duas décadas. Embora suas concepções variem conforme a autora ou autor, parece haver elementos comuns que permitem delinear uma noção de midiatização, a partir da qual podem ser construídas derivações teóricas e metodológicas. A partir de pesquisa bibliográfica, o trabalho explora esses pontos similares que parecem sugerir a midiatização como (a) a articulação, não "influência" ou "efeitos", entre a (b) mídia, entendida, simultaneamente, como instituição, tecnologia e linguagem e (c) práticas sociais, compreendidas como ações cotidianas em seu contexto histórico, econômico e social. Essa perspectiva é contextualizada nas Teorias da Comunicação, como alternativa a alguns modelos transmissivos que destacam a separação entre "mídia" e "sociedade".
\end{abstract}

\section{Palavras-chave}

Midiatização. Práticas sociais. Teoria da comunicação. Epistemologia.

\section{Introdução}

Iniciar este texto com a palavra "teoria" no título pode sugerir algo além de suas deixando claros seus limites, em contraste, talvez, com o que a presença da palavra "teoria" no título possa sugerir. A elaboração de uma construção teórica está além das pretensões do texto. Trata-se de pensar algumas abordagens para a midiatização desenvolvida a partir dos estudos teóricos e empíricos elaborados por diversas autoras e autores, nos últimos anos, sobre as relações entre o ambiente midiático e as práticas sociais. É, portanto, um exercício reflexivo e eventualmente conceitual, e, certamente, jamais prescritivo. 
O conceito de midiatização vem recebendo uma atenção crescente na pesquisa em Comunicação, ao menos desde o início dos anos 2000. Expressões como "midiatizada" ou "midiatização" são correntes nas pesquisas da área, dando títulos a livros, artigos e eventos, dentre eles o livro Compós 2012, Mediações e midiatização (MATTOS; JANOTTI; JACKS, 2012), e ao menos duas Linhas de Pesquisa em Programas de Pós-Graduação, Processos Midiatizados de Interação Social, na Pontifícia Universidade Católica de Minas Gerais (PUC-MG), e Midiatização e Processos Sociais, na Unisinos, além de pesquisas críticas de Rüdiger (2015), Marcondes (2016) ou Carvalho (2016).

Essa vitalidade sugere, de um lado, o potencial hermenêutico do conceito em relação a fenômenos contemporâneos. A ideia de midiatização parece revestir-se de mais força quando pensada dentro de uma sociedade na qual a presença das mídias, em qualquer espaço público, é imediatamente visível. Por outro lado, a presença do fenômeno e do conceito levanta questões epistemológicas a seu respeito, como seu alcance, especificidade e limites interpretativos.

Se há considerável produção e utilização, por outro lado a atenção dada às questões específicas dessa ideia está longe de ser igual. É possível observar o uso de "midiatização" ou "midiatizado" em livros e artigos sem uma maior elaboração no sentido de delimitar o alcance empírico dessa construção teórica. Não faltam, por outro lado, pesquisas rigorosas sobre o conceito, procurando entender seus fundamentos e sua operacionalização metodológica (PARES, 2008; SGORLA, 2009; ADOLF, 2011; AVERBECK-LIETZ, 2011; SODRÉ, 2004; FAUSTO NETO et al., 2008).

Mais ainda, como sugere Livingstone (2008; 2009), o uso da expressão parece estar longe de qualquer consenso, sobretudo no universo anglo-saxônico. Se, nas pesquisas brasileiras e, em certa medida, latino-americanas, o conceito de "midiatização" diferencia-se claramente da noção de "mediação", associada aos trabalhos de Martin Barbero (1997), por outro lado, é fácil encontrar, nas pesquisas europeias, certo uso intercambiável dos termos "mediatization", "midialization" (THOMPSON, 1998) e "mediation" (COULDRY, 2006; 2008), ou "midiality" (MEITZ, 2011), em contextos semelhantes e para se referir a elementos próximos.

Ao mesmo tempo, enquanto nas pesquisas brasileiras, há uma distinção do conceito em relação às "mediações", por outro lado, nota-se uma considerável abrangência dos fenômenos cobertos sob essa expressão. Isso ocorre desde elaborações teóricas das formas e usos do conceito até seu uso como sinônimo de presença ou representação de um tema na mídia - no sentido, por exemplo, da "midiatização da comida" (LIMA, 2011; JACOB, 2012) ou "midiatização da saúde" (FERRAZ, 2013). 
A leitura dessas pesquisas indica que a disseminação do conceito e, mais ainda, da expressão, parece acontecer sem igual preocupação em definir do que se está, de fato, falando. Não, evidentemente, no sentido de propor uma definição única, o que engessaria a noção e eliminaria sua capacidade interpretativa, mas na busca de algum rigor em seu uso. A excessiva elasticidade de um conceito, argumenta Schott (2009), mina seu potencial interpretativo, ao definir um número ilimitado de fenômenos, uma concepção perde a especificidade que justifica seu emprego.

Este texto propõe uma perspectiva teórica para o conceito de midiatização, entendida como a articulação entre o ambiente midiático e as práticas sociais dentro de um contexto histórico, social e político. Essas proposições tomam como base estudos empíricos realizados na última década combinados com uma pesquisa bibliográfica sobre o conceito.

A ideia ancora-se em três aspectos: (1) a articulação, não "influência" ou "efeitos", entre a (2) mídia, entendida, simultaneamente, como instituição, tecnologia e linguagem e (3) práticas sociais, compreendidas como ações cotidianas em seu contexto de desigualdades e conflitos históricos, econômicos e sociais.

0 texto a seguir trilha esses três aspectos, precedidos de uma breve consideração sobre o posicionamento da noção de "midiatização" no contexto dos estudos de Comunicação.

\section{A midiatização no campo teórico da Comunicação}

A pesquisadora ou pesquisador interessado na palavra "midiatização" não terá dificuldades para localizar seu tema. Alguns dados quantitativos, sem pretensão de delinear completamente o cenário, indicam o raio de disseminação do assunto.

Uma busca inicial no Banco de Teses e Dissertações da Capes aponta 369 resultados com a palavra "midiatização" no título, 142 com "mediatizada" e 78 para "midiatizado". Variando a grafia para "mediatização", os números são 45, 109 e 57, combinando um total de 800 trabalhos que, de um modo ou de outro, encontram no conceito um operador epistemológico de relevância para a pesquisa.

Nas principais redes de livrarias, os títulos brasileiros disponíveis referem-se à midiatização de diversos fenômenos e práticas, como eleições (FAUSTO NETO, 2012a), ciência (FAUSTO NETO, 2012b), religião (GOMES, 2010; GASPARETTO, 2011), drogas (CHAGAS, 2012), 
revistas femininas (ALIGHIERI, 2015) e, em termos mais abrangentes, da sociedade (GOMES, 2006; FAUSTO NETO et al., 2008; 2010; HJARVARD, 2011).

No espaço das publicações acadêmicas, o Portal de Periódicos da Capes registra 76 artigos distribuídos como produção qualificada, usando "midiatização", outros 29 para "mediatização". O acompanhamento e a discussão dessa produção vêm sendo tematizada por vários pesquisadores, em perspectivas diferentes, como nas abordagens de Marcondes Filho (2015), Rüdiger (2015) e Gomes (2017). Há, igualmente, estudos dedicados à compreensão do conceito, como os trabalhos de Sodré (2004), Fausto Neto (2006; 2008); Braga (2007), Ferreira (2010a; 2010b), Mattos, Janotti e Jacks (2012), Carvalho (2016), Gomes e Faxina (2016) e Gomes (2017)

A produção estrangeira sobre o assunto parece aportar nas pesquisas brasileiras, levando em consideração as traduções disponíveis, a partir de Hjarvard (2012; 2013; 2015), Strömback (2008; 2011) e Hepp (2012).

Esses números ajudam a dimensionar a presença do conceito nas pesquisas brasileiras de Comunicação, embora, evidentemente, não permitam ver as maneiras desse uso. Sua expansão sugere sua adoção pela área e um direcionamento do próprio campo no sentido de buscar compreender práticas sociais em sua relação com os meios de comunicação. 0 crescimento do assunto pode ser visto como um indicador de seu potencial interpretativo.

Quem se lança à leitura e à compreensão dessa produção pode notar ao menos três principais tipos de produção baseadas dentro do conceito de midiatização, levando em consideração tanto seus referenciais teóricos originários, quanto sua operacionalização teóricometodológica e área de abrangência. E, antes de tudo, vale lembrar que essa é uma sistematização tentativa, panorâmica, na qual as inúmeras diferenças internas são tiradas de foco em prol da possibilidade da clareza.

Um primeiro eixo ou bloco temático constitui-se a partir das pesquisas brasileiras realizadas na Unisinos, na Linha de Pesquisa Midiatização e Processos Sociais. O conceito de midiatização é operacionalizado pelos quatro pesquisadores e uma pesquisadora da linha a partir de pontos de vista diversos. Nota-se alguma ancoragem nas pesquisas de Verón (1986; 2013), da Filosofia e da Sociologia nos trabalhos do grupo. Se for possível apontar algo comum, com os riscos e possibilidades de um olhar externo, é não fazer do processo de midiatização uma abordagem "midiacêntrica" do social, com o conceito pensado em um contexto histórico amplo, em diálogo com outros referenciais teóricos. 
0 segundo aspecto refere-se às pesquisas anglo-saxônicas. Em linhas gerais, nelas, a presença da mídia enquanto instituição e dispositivo tecnológico é mais evidente, e entende-se a mídia como - parafraseando Hjarvard (2008) - "agente de mudança social".

Em certo aspecto, trabalhos de Hepp, Krotz e Hjarvard permitem observar uma perspectiva de centralidade da mídia, entendida como instituição, (apesar da advertência de Couldry (2008) sobre os riscos desse tipo de deslocamento em relação ao social) responsável, ainda que parcialmente, por algumas transformações do mundo social. As matrizes teóricas desses trabalhos mantém uma referência constante a estudos anteriores sobre mídia e sociedade, deixando em segundo plano abordagens das Ciências Sociais ou da Filosofia.

Há, nesses estudos, perspectivas distintas a respeito do processo de midiatização, trabalhando em uma perspectiva de caráter mais próxima da noção de uma "realidade mediada", como em Couldry e Hepp (2016) ou, ainda, nas ramificações institucionais e sociais da mídia como espaço de intermediação de outros espaços sociais, sugerida por Hjarvard (2008). Nos dois casos, observa-se o posicionamento da mídia como um espaço importante - apesar do cuidado recomendado por Couldry (2006) em à busca de um "centro mediado" da sociedade.

Finalmente, a pessoa interessada em explorar essa produção bibliográfica tende a encontrar o que parece ser um uso indiscriminado de "midiatização" e palavras correlatas para significar a presença ou veiculação de algo na mídia. Neste terceiro grupo, seria possível mencionar um uso não conceitual de "midiatização", colocada mais como uma qualidade ou característica.

Diante da riqueza e potencialidade conceitual dessas abordagens, busca-se, na sequência, um exercício de sistematização combinatória dessas perspectivas. A proposta é pensar a midiatização como a articulação entre o ambiente da mídia e práticas sociais.

Vale pensar, de maneira mais próxima, cada um dos termos dessa proposição. Qualquer um dos três - "articulação", "ambiente campo da mídia", "práticas sociais" - poderia ser um ponto de entrada. Entende-se, no entanto, que começar pela noção de "articulação" permite indicar o potencial interpretativo do conceito de midiatização em relação a algumas abordagens da área.

\section{Articulação: pensando além das dicotomias}

A noção de articulação operacionalizada aqui é pensada a partir de Hall (1996) e Slack (1996). Hall desenvolve seu conceito de articulação para entender as relações entre cultura e 
política dentro de uma "interação radical", sem especificar a dominação entre ambas de maneira unilateral, mas destacando o aspecto dinâmico e móvel da relação. Hall (1996) utiliza a comparação de um caminhão, no qual a boleia e a carroceria estão articuladas: os movimentos de uma interferem na outra sem, necessariamente, uma relação de espelhamento ou subordinação. Ambas estão conectadas, mas mantendo sua autonomia e características próprias. Ao mesmo tempo em que elimina qualquer noção mecanicista, Hall também não afirma que as duas partes de qualquer articulação estão em pé de igualdade. Ao contrário, trata-se - e aqui recorro um estudo anterior de Hall (1981) - de uma "negociação" de sentidos, práticas e significados dentro de uma relação construída e reconstruída a cada momento.

O conceito de articulação entra nesta proposta sobre midiatização como uma tentativa de superar algumas dictomias persistentes entre mídia e sociedade, nos estudos de Comunicação, pautadas em modelos transmissivos da mídia.

Historicamente, parte considerável da pesquisa da área preocupou-se em conhecer os diversos aspectos da relação entre a "mídia" e a "sociedade". Essa abordagem referia-se a um momento no qual era possível falar dos "meios" de comunicação como um conjunto à parte, em relação ao restante da sociedade. Os "meios de comunicação" eram instituições, particulares ou estatais, produtoras de um tipo de mensagem - a "comunicação de massa" - dirigida a um público quase totalmente desprovido de condições de divulgar suas próprias mensagens para além de um círculo relativamente restrito de pessoas.

No entanto, as transformações sociais, institucionais e tecnológicas, ocorridas desde meados dos anos 1990, descortinaram um panorama no qual o modelo "mídia e sociedade" mostrou-se insuficiente como operador epistemológico.

A mídia que ocupava, institucionalmente, um lugar à parte na sociedade, passa a ocupar um espaço dentro das práticas sociais. A "mídia" deixa de ser localizável em termos de espaço e tempo - a "televisão", o "horário da novela", o "programa no rádio" - e passa a entremear as atividades cotidianas. Em linhas gerais, a noção de midiatização é uma tentativa de deixar de pensar em termos de "mídia e" determinada prática para trabalhar a "mídia com" ou "mídia na" sociedade. Não se trata de uma simples alteração de nome, mas de pensar um processo contemporâneo de mudanças até nos níveis imediatos do cotidiano (WELLMANN, 2001; RAINIE; WELLMANN, 2012; LINKE, 2011; TURKLE, 2012; JANSSON, 2017).

Livinstone (2009) sintetiza essa passagem ao assinalar como, nos anos recentes, o que seria um estudo sobre "mídia e política" (media and politics) passa a ser pensado como "mediação da política" ou "política mediada" (mediated Politics). Dessa maneira, não é possível 
falar em "reflexo", "influência", "efeitos" ou qualquer palavra correlata, mas, antes, em "articulação", no sentido de Hall, entre as práticas sociais e a mídia.

De certa maneira, o nome "midiatização" sugere, pelo sufixo "ação", a ideia de um processo de mudança ou atribuição, a um elemento, de características do outro, mas podendo conservar algumas de suas propriedades. Falar de "midiatização" significa pensar em termos de uma relação estabelecida com a mídia que ultrapassa a simples ligação, como em "mídia e sociedade", para trabalhar um processo de entrelaçamento e transformação, a "midiatização da sociedade".

Deixa-se de lado a possibilidade de pensar "mídia" e "sociedade" como categorias estanques, em um delicado e incerto balanço de poder e influência recíproca, para pensar de que maneira a mídia articula-se nos entremeios das práticas sociais e vice-versa. É, também, uma tentativa de escapar ao midiacentrismo às vezes implicado na pergunta sobre "efeitos", apresentada de várias maneiras (ZENGOTITA, 2005; HJARVARD, 2008; HEPP, 2012).

Pensar a sociedade articulada com os meios é diferente de entender uma relação entre meios e sociedade, na qual os termos estariam mais distantes. Em uma perspectiva de "mídia e sociedade", aos meios de comunicação era atribuído um lugar central, a partir do qual era possível não apenas "influenciar" a sociedade, mas, conforme a perspectiva teórica adotada, promover transformações políticas e sociais.

Algumas das perspectivas de midiatização evitam essa dicotomia, relativizando o poder da mídia diante de sua pulverização pelas diversas instâncias do cotidiano, mas considerando as desigualdades de poder existentes, sobretudo em relação aos conglomerados de mídia detém uma significativa força política e econômica.

O conceito de articulação, em sua mobilidade e dinâmica, ocupa um espaço fundamental para se pensar a midiatização da sociedade para além do imobilismo dos efeitos ou de movimentos mecanicistas. Ele procura oferecer um caminho teórico para pensar a relação entre os dois termos, "ambiente das mídias" e "práticas sociais", vistos nos próximos itens.

A noção de articulação, em Hall (1996), parece incluir justamente uma perspectiva de deslocamento de qualquer elemento central, substituído pela instabilidade do movimento expressa, de certo modo, quando se menciona a ideia de "processo" de midiatização. Esse movimento, no entanto, não parece ser aleatório nem completamente difuso: o tecido de "circuitos mistos", nas palavras de Braga (2015, p. 24) parece ter um ponto de confluência no momento dessa articulação. 


\section{A mídia como ambiente}

A noção de "mídia" é, de longe, uma das mais utilizadas no campo de estudos da Comunicação. No entanto, assim como em outros casos, trata-se de um conceito às vezes mais tomado como "dado" do que construído: "mídia" seriam os "meios de comunicação" - definição que está longe de encontrar unanimidade entre pesquisadores, sobretudo pela abrangência do campo semântico coberto por ela.

Isso cria um dificuldade: como falar em "midiatização" se o conceito de "mídia", um dos polos do processo, demanda uma diferenciação maior? Trabalhar uma noção de "midiatização" implica considerar diversas acepções de "mídia" e pensar quais delas podem ser relevantes para a construção do conceito.

Busca-se uma abordagem multidimensional da questão, evitando interpretações redutoras, como colocá-los à parte em relação ao contexto social e histórico com o qual se relacionam. Neste ponto, a argumentação que se segue desenvolve, sobretudo os pontos formulados por Meyrowitz (1993; 1994; 1999), Lévy (1999), Martino (2008) e Sousa (2009).

A noção de mídia, nos estudos sobre midiatização, parece referir-se, ao mesmo tempo, a um conjunto de dispositivos tecnológicos, a um aglomerado de instituições sociais, estatais ou particulares, e uma forma ou linguagem específica de elaboração de uma mensagem. Ferreira (2007) aciona a perspectiva de "dispositivos" na interação entre o que denomina "processos sociais" e "processos de comunicação". Em diálogo com essa proposta, acrescenta-se, neste caso, a perspectiva de uma "lógica dos meios", no sentido de Meyer (2002), para pensar os elementos do processo.

Em sua forma primeira, a mídia pode ser entendida como os dispositivos tecnológicos responsáveis por efetuar a ligação entre pessoas em graus variados de distância. 0 foco está no chamado "suporte" da mensagem considerado em sua materialidade - da mídia impressa às digitais. A presença, disponibilidade e uso desses dispositivos no cotidiano são decisivos para o processo de midiatização.

Certamente seria considerar outros suportes, como voz ou escrita, como "mídia", na esteira, por exemplo, da argumentação de Baitello (1998; 2005). No entanto, o recorte para a definição de "mídia" refere-se à presença de aspectos técnicos de reprodução como diferença específica (MEYROWITZ, 1985). Tomando essa trilha, não se exclui, de maneira alguma, o aspecto de "mídia" do corpo ou da escrita, mas procura-se um recorte em relação ao alcance de 
larga escala proporcionado pelo suporte tecnológico dessas mídias, fundamental para o processo de midiatização.

Essa materialidade técnica e tecnológica, no entanto, não pode ser vista de maneira isolada, mas inserida em complexos sistemas de produção, pautados em uma lógica voltada para a venda e para o lucro, dentro da qual essa materialidade é convocada a se tornar o instrumental para a veiculação de determinados elementos.

Isso leva à segunda dimensão da palavra "mídia" na midiatização. A palavra "mídia" é usada, também, para designar as instituições sociais responsáveis por produzir e divulgar informações. A noção de "meios de comunicação", ampliada além da materialidade da tecnologia, refere-se ao aparato de produção de mensagens, em particular às chamadas "empresas de comunicação" (LIMA, 2001; 2011; BOLAÑO, 2014).

0 elemento tecnológico está vinculado à demandas empresariais responsáveis por alguns dos principais agenciamentos do mundo social. 0 conceito de "mídia" como "empresa de comunicação" não se refere, exclusivamente, à produção de conteúdo, embora, também o englobe.

Inclui, também, como "mídia", empresas de gerenciamento de conteúdo produzido por consumidores. 0 chamado "conteúdo produzido por usuários", matéria-prima das redes sociais, pode ser "produzido" pelos usuários, mas seu gerenciamento e sua distribuição são feitos a partir das empresas responsáveis pelas redes.

"Mídia", finalmente, tem um significado próximo ao de "forma", no sentido de uma "linguagem" ou "código semiótico", derivado das possibilidades e dos limites das tecnologias e das instituições às quais elas estão ligadas (COHN, 1998; FISKE, 1985; 1989; MANOVICH, 2001; SANTAELLA, 2007; MARTINO, 2014). Em seu sentido mais simples, a "linguagem" da mídia refere-se às especificidades formais de adequação de qualquer mensagem veiculada em um meio.

A título de exemplo, vale recordar as limitações de caracteres de uma rede como o Twitter, ou de conteúdo presentes em quase todas as redes. Falar de uma "linguagem" da mídia é levar em consideração as maneiras formais de codificação derivadas de da materialidade técnica dos meios e dos agenciamentos institucionais de sua produção.

O conjunto dessas três dimensões da mídia - técnica, instituição e linguagem - formam o que Meyrowitz (1999) define como "ambiente midiático". A proposição indica a ubiquidade da mídia no cotidiano. Isso presume uma alteração nas práticas sociais anteriores que, se nem por isso deixam de existir, ganham novos contornos em sua articulação com a mídia. 
A noção de "ambiente" sugere uma presença cotidiana da mídia, mesmo que invisível. Wellman (2001) e Rainie e Wellman (2012) argumentam, aliás, que o potencial de mudança no cotidiano de um dispositivo midiático realiza-se plenamente no momento em que ele se torna invisível: ninguém se espanta com o telefone, por exemplo, e isso faz dele especialmente poderoso. Algo semelhante poderia ser dito das mídias digitais ou dos smartphones contemporâneos: o fato de sua presença passar despercebida no cotidiano sugere a assimilação das transformações provocadas por eles.

Pensados como um ambiente em sua tripla dimensão, a noção de mídia expande-se, mas não de maneira indefinida: a articulação com práticas sociais não se traduz na imanência de algo eternamente novo, pautado pela velocidade dos dispositivos. Ela mostra como certos aspectos das práticas sociais mais corriqueiras, ao se articularem com esse ambiente, ganham outros contornos e aspectos.

\section{Práticas sociais como dinâmicas de significado}

A noção de "práticas sociais" nasce da sociologia, e refere-se, em termos iniciais, ao conjunto de ações executadas por indivíduos e comunidades a partir da interação com os outros. Trata-se, também, de um conceito relacional de ação, trabalhado, sobretudo dentro de uma “teoria da prática”, por Bourdieu (2000; 1998), ao colocar em diálogo o conceito de "ação social”, em Weber (1991) com a perspectiva crítica de Marx (2015). São definidas como "práticas sociais" as atitudes e os comportamentos realizados no âmbito de um espaço social e, sobretudo, aquelas dirigidas a outras pessoas - o sentido do "social" aqui se realiza na relação reciprocamente orientada e que tem lugar fora do âmbito das decisões estritamente subjetivas.

As práticas sociais, recorda Bourdieu (2000), tem como objeto aquilo que ganha proeminência ou algum tipo de valor dentro do espaço social. Estão vinculadas, também, à criação de formas de distinção social, de criação e manutenção de hierarquias e de poder.

Dessa maneira, seguindo Bourdieu (2000), incluem-se sob a noção de "prática social", atividades, ações, gostos e modalidades da existência cotidiana, como o vestir ou o falar que, voltados para os outros, vinculam-se, ao mesmo tempo, a um conjunto de práticas anteriores providas de um valor e de um sentido e à antecipação das formas de reconhecimento, lucro simbólico e definição de espaços sociais igualmente decorrentes da prática. 0 ponto específico das práticas sociais é o fato de serem elaboradas tendo como referência outras pessoas, não 
apenas o praticante. Suas motivações e expectativas de retorno são, igualmente, pautadas pela reciprocidade assimétrica das relações.

Isso parece implicar dois elementos principais relacionados ao conceito de midiatização. Em primeiro lugar, trata-se de uma perspectiva relacional, no qual a interação com o outro é um ponto fundamental: não existe prática social sem referência a um contexto social que ao mesmo tempo a produz e a legitima. Esse "contexto social", no entanto, não existe enquanto entidade abstrata, mas se materializa no conjunto de relações cotidianas. A prática social implica, nesse sentido, uma relação de comunicação.

Uma perspectiva de midiatização compreende as práticas sociais articuladas com o ambiente das mídias digitais, levando em conta as continuidades e rupturas inerentes a isso. Entende-se que as práticas sociais não perdem suas características específicas no âmbito da midiatização; ao contrário, ganham desdobramentos e possibilidades inexploradas. As relações profissionais e afetivas, as práticas políticas e econômicas, os estilos de vida e as ações reciprocamente orientadas conservam suas características fundamentais. No entanto, são implementadas com outras possibilidades quando articuladas com o ambiente midiático.

Essa perspectiva não exclui, portanto, as transformações do ambiente midiático e das práticas sociais, mas localiza essas alterações e procura operacionalizações metodológicas a fim de compreender e dimensionar essas mudanças. Quando mediadas, outros aspectos de práticas sociais tornam-se possíveis, assim como a potencialização de elementos até então latentes. A figura abaixo sugere a perspectiva de interação nessa concepção de midiatização:

Figura 1 - Elementos possíveis de um processo de midiatização

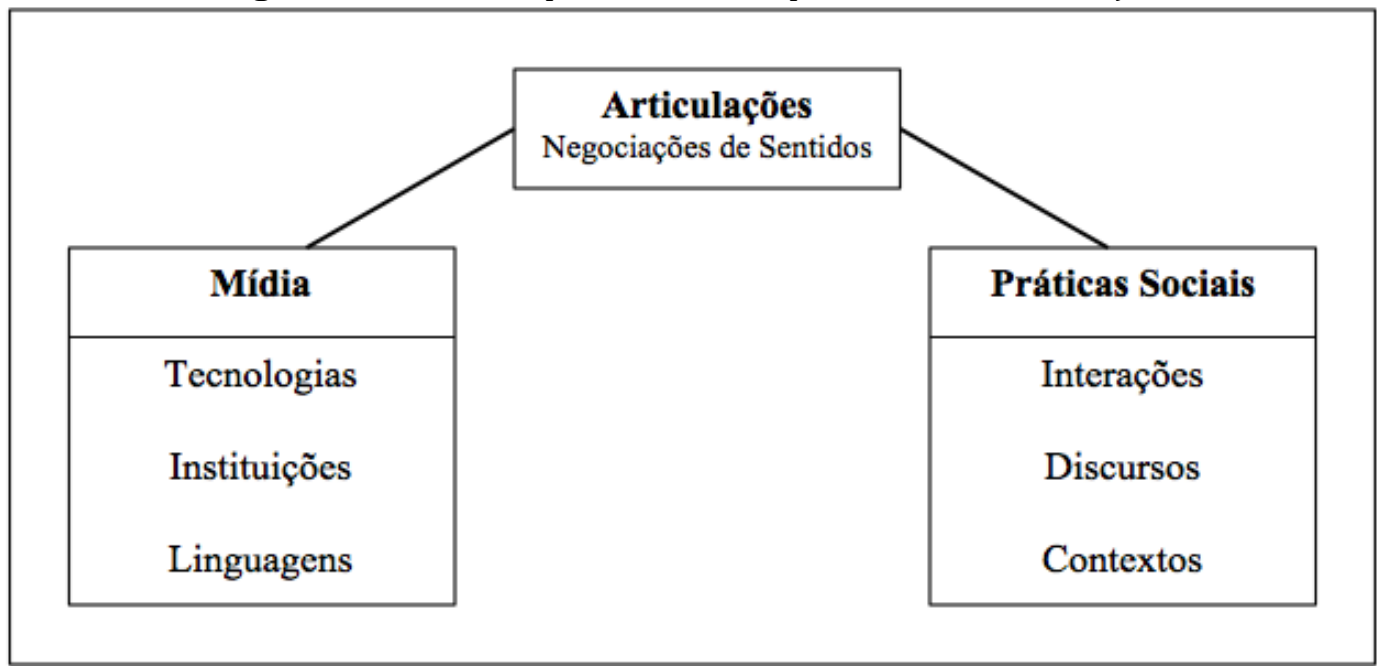

Fonte: Elaborado pelo autor a partir de Verón (1997), Sodré (2004), Fausto Neto (2006), Braga (2006), Ferreira (2007; 2009), Gomes (2017) e Martino (2016). 
O processo de midiatização acontece quando alguns aspectos das práticas sociais são reconfigurados para se ajustar às demandas decorrentes de sua articulação com o ambiente midiático - por exemplo, nos relacionamentos afetivos ou na política. Assim, para trazer mais um exemplo, no âmbito da midiatização da religião, a simples transmissão de uma cerimônia religiosa não parece constituir um indício de "midiatização", mas de "mediação" no sentido dado ao termo nas pesquisas anglo-saxônicas (como "mediation"). No entanto, quando os aspectos da cerimônia ou do ritual são planejados para sua veiculação midiática, pode-se observar uma mudança -indício para o processo de midiatização (COTTLE, 2006; HJARVARD, 2008b; 2012; HOOVER, 2009; MARTINO, 2012; 2016).

A proposta de midiatização entendida aqui procura um deslocamento da mídia do lugar central e não considera as práticas sociais, ao menos nos espaços urbanos contemporâneos, atuando de maneira totalmente independente da mídia. Entendido como articulação, o processo de midiatização parece caracterizar-se por esse duplo deslocamento: trata-se do momento de entrelaçamento da mídia com as práticas sociais. Além disso, trata-se de um momento de tensão entre ações, usos e significados entre as práticas sociais e o ambiente das mídias.

\section{Considerações finais}

Afirmando-se, nas últimas décadas, como um tema importante nos estudos de Comunicação, o conceito de midiatização desafia qualquer interpretação redutora. Ao mesmo tempo, é possível observar, a partir de seus usos, algumas trilhas convergentes, para pensar o contemporâneo a partir de um ponto de vista das pesquisas em mídia e comunicação.

Pensado, de maneira inicial, como a articulação entre um ambiente midiático e de práticas sociais, procura-se destacar não apenas a complexidade do processo, mas também sua dinâmica. Nesse aspecto, o conceito de midiatização procura situar-se entre elementos anteriormente considerados polos de dicotomias, como "mídia e sociedade", "sociocentrismo ou mediacentrismo", "ruptura ou continuidade" dentro de uma historicidade, na qual se entrelaçam aspectos de um ambiente midiático e transformações sociais.

O lugar metodológico da perspectiva da midiatização parece situar-se no âmbito da articulação. Não é o ambiente midiático — dimensão reservada a uma reflexão sobre a técnicanem as práticas sociais, objeto das Ciências Sociais,. A articulação desses elementos emerge como espaço de investigação para as pesquisas em midiatização. 
A perspectiva epistemológica do conceito de midiatização parece pressupor uma dinâmica de conflitos e cooperações, tensionamentos e cumplicidades entre as práticas sociais e o ambiente midiático no qual, ao mesmo tempo, elas são criadas e contribuem para criar (SCHULZ, 2004; HEPP; HJARVARD; LUNDBY, 2009; KROTZ, HEPP, 2011).

Essa perspectiva sublinha o que há de específico nessa relação, podendo ser operacionalizada metodologicamente, a partir de diversas entradas e aportes que combinam considerações sobre o social, sem se situar, necessariamente, dentro das Ciências Sociais, e sobre o técnico-midiático, evitando, porém, se localizar em uma concepção da mídia como ator central das práticas sociais - o processo encontra como agentes, em todas as escalas, o humano.

\section{Agradecimentos}

Uma versão preliminar desse texto foi apresentada na conferência de abertura do II Congresso Nacional de Estudos Comunicacionais (Conec) da PUC MG, em Poços de Caldas, nos dias 30 e 31 de outubro de 2017. 0 autor agradece as contribuições recebidas na ocasião, assim como a leitura e os comentários da Profa. Dra. Angela C. S. Marques (Universidade Federal de Minas Gerais) e os diálogos sobre midiatização com as pesquisadoras Vivyane Garbelini (Cásper Líbero) e Melina Sternberg (Pontifícia Universidade Católica de São Paulo) e das/dos pareceristas para a discussão e publicação deste artigo.

\section{Referências}

ADOLF, M. Clarifying mediatization: sorting through a current debate. Empedocles: European Journal for the Philosophy of Communication, Bristol, v. 3, n. 2, p. 153-175, 2011.

\section{ALIGHIERI, B. As revistas femininas e seus contratos de leitura no ambiente da} midiatização. Curitiba: Appris, 2015.

AVERBECK-LIETZ, S. French and latin american perspectives on mediation and mediatization: a lecture note from Germany. Empedocles: European Journal for the Philosophy of Communication, Bristol, v. 3, n. 2, p. 177-195, 2011.

BAITELLO, N. A era da iconofagia. São Paulo: Hackers, 2005.

BAITELlO, N. Comunicação, mídia e cultura. São Paulo em Perspectiva, São Paulo, v. 12, n. 4, p. 11-16, 1998. 
BARBERO, J. M. Dos meios às mediações. Rio de Janeiro: Ed. UFRJ, 1997.

BOLAÑO, C. R. S. Prefácio. In: CARVALHO, J. M.; MAGNONI, A. F.; PASSOS, M. Y. (Org.). Economia política da comunicação. São Paulo: Cultura Acadêmica, 2014.

BOURDIEU, P. Raisons pratiques. Paris: Seuil, 1998.

BOURDIEU, P. Le sens pratique. Paris: Minuit, 2000.

BRAGA, J. L. Experiência estética e midiatização. In: LEAL, B. S.; GUIMARÃES, C.; MENDONÇA, C. Entre o sensível e o comunicacional. Belo Horizonte: Autêntica, 2010.

BRAGA, J. L. Midiatização como processo interacional de referência. In: MÉDOLA, A. S.; ARAUJO, D. C.; BRUNO, F. Imagem, visibilidade e cultura midiática. Porto Alegre: Sulina, 2007. p. 141168.

BRAGA, J. L. Lógicas da mídia, lógicas da midiatização? In: FAUSTO NETO, A.; ANSELMINO, N. R.; GINDIN, I. L. Relatos de investigaciones sobre mediatizaciones. Rosário: UNR Editora, 2015.

CARVALHO, C. A. Midiatização: investigações brasileiras e europeias e o midiacentrismo. In: COMPÓS, 25., 2016, Goiânia. Anais... Goiânia: Compós, 2016.

CHAGAS, A. Midiatização das drogas. Santa Maria: Ed. UFSM, 2012.

COHN, G. A atualidade do conceito de Indústria Cultural. In: MOREIRA, A. (Org.). Sociedade global. Petrópolis: Vozes, 1998.

COTTLE, S. Mediatized rituals: beyond manufacturing consent. Media Culture \& Society, London, v. 28, n. 3, p. 411-32, 2006.

COULDRY, N. Listening beyond the echoes. London: Paradigm, 2006.

COULDRY, N. Mediatization or mediation? Alternative understandings of the emergent space of digital storytelling. New Media and Society, London, v. 10, n. 3, p. 373-391, 2008.

COULDRY, N.; HEPP, A. The mediated construction of reality. London: Polity, 2016.

FAUSTO NETO, A. Fragmentos de uma "analítica" da midiatização. Matrizes, São Paulo, v. 1, n. 2, p. 89-105, 2008.

FAUSTO NETO, A. Midiatização, prática social - prática de sentido. In: COMPÓS, 15., 2006, Bauru. Anais... Bauru: COMPÓS 2006.

FAUSTO NETO, A. et al. Midiatização e processos sociais: aspectos metodológicos. Santa Cruz do Sul: Ed. Unisc, 2010.

FAUSTO NETO, A. et al. Midiatização e processos sociais na América Latina. São Paulo:

Paulus, 2008. 
FERRAZ, L. M. R. A doença sob a ótica da midiatização. In: CONGRESSO DE ESTUDANTES DE PÓS-GRADUAÇÃO EM COMUNICAÇÃO, 6., 2013, Rio de Janeiro, RJ. Anais... Rio de Janeiro: UERJ, 2013.

FERREIRA, J. Dos objetos separados à circulação midiática como questão comunicacional. In: FAUSTO NETO, A. et al. Midiatização e processos sociais: aspectos metodológicos. Santa Cruz do Sul: Ed. Unisc, 2010a. p. 67-78.

FERREIRA, J. Midiatização: dispositivos, processos sociais e de comunicação. E-Compós, Belo Horizonte, v. 10, n. 3, p.1-13, 2007.

FISKE, J. Television culture. London: Routledge, 1985.

FISKE, J. Understanding popular culture. London: Routledge, 1989.

GASPARETTO, P. R. Midiatização da religião. São Paulo: Paulinas, 2011.

GOMES, P. G. Da igreja eletrônica à sociedade em midiatização. São Paulo: Paulinas, 2010.

GOMES, P. G. Dos meios à midiatização. São Leopoldo: Ed. Unisinos, 2017.

GOMES, P. G.; FAXINA, E. Midiatização. São Paulo: Paulinas, 2016.

GOMES, P. G. Filosofia e ética da comunicação na midiatização da sociedade. São Leopoldo: Ed. Unisinos, 2006.

HALL, Stuart. Encoding / decoding. In: HALL, D. et al. (Ed.). Culture, media, language: working papers in cultural studies, 1972-79. London: Hutchinson, 1980. p. 128-138.

HALL, S. On postmodernism and articulation: an interview with Stuart Hall. In: MORLEY, D.; KUAN-HSING, C. (Ed.). Stuart Hall: critical dialogues in cultural studies. London: Routledge, 1996.

HEPP, A. Cultures of mediatization. London: Polity, 2012.

HEPP, A.; HJARVARD, S.; LUNDBY, K. Mediatization: empirical perspectives: an introduction to a special issue. Communications, Berlin, v. 35, n. 3, p. 223-228, 2010.

HJARVARD, S. Doing the right thing: media and communication studies in a mediatized world. Nordicom Review, Göteborg, v. 33, n. 1, p. 27-34, 2012.

HJARVARD, S. The mediatization of religion: a theory of the media as agents of religious change. Northern Lights, Copenhagen, v. 6, n.1, p. 9-27, 2008b.

HJARVARD, S. The mediatization of society. Nordicom Review, Göteborg, v. 29, n. 2, p. 105-34, 2008a. 
HJARVARD, S. Da mediação à midiatização: a institucionalização das novas mídias. Revista Parágrafo, São Paulo, v. 3, n. 2, 2015.

HJARVARD, S. The mediatization of culture and society. Londres: Routledge, 2013.

HOOVER, S. Complexity: the case of religious cultures. In: LUNDBY, K. (Org.). Mediatization: concept, changes, consequences. New York: Peter Lang, 2009.

JACOB, H. Gastronomídia: ambientes midiáticos e as linguagens da comida e da cozinha. Communicare, São Paulo, v. 12, n. 02, p. 113-125, 2012.

KROTZ, F. Mediatization: a concept with which to grasp media and societal change. In: LUNDBY, K. (Org.). Mediatization: concept, changes, consequences. Nova York: Peter Lang, 2009. p. 2140 .

KROTZ, F.; HEPP, A. A concretization of mediatization: how mediatization works and why 'mediatized worlds' are a helpful concept for empirical mediatization research. Empedocles: European Journal for the Philosophy of Communication, Bristol, v. 3, n. 2, p. 137-152, 2011.

JANSSON, A. Mediatization and mobile lives. Londres: Routledge, 2017.

LÉVY, P. Cibercultura. São Paulo: Ed. 34, 1999.

LIMA, L. H. S. Os processos de midiatização da cozinha paulista: do Arraial à metrópole. 2011. Dissertação (Mestrado em Comunicação) - Universidade Anhembi Morumbi, São Paulo, 2011.

LIMA, V. Mídia: teoria e política. São Paulo: Perseu Abramo, 2001.

LIMA, V. A. Regulação das comunicações. São Paulo: Paulus, 2011.

LIVINGSTONE, S. Coming to terms with 'mediatization'. In: LUNDBY, K (Org.). Mediatization: concept, changes, consequences. New York: Peter Lang, 2009. p. ix-xiii.

LIVINGSTONE, S. On the mediation of everything. Journal of Communication, Hoboken, v. 59, n. 1, p. 1-18, 2008.

LUNDBY, K. Introduction: 'mediatization' as key. In: LUNDBY, K. (Org.). Mediatization: concept, changes, consequences. New York: Peter Lang, 2009. p. 1-20.

MANOVICH, L. The language of new media. Massachussets: MIT Press, 2001.

MARCONDES FILHO, C. A virada comunicacional. Ou porque os estudos de "midiatização", de hábito e da Teoria dos Media passam ao largo da comunicação. Revista Famecos, Porto Alegre, v. 22 , n. 2, p. 134-145, 2015.

MARTINO, L. C. Pensamento comunicacional canadense: as contribuições de Innis e McLuhan. Comunicação, Mídia e Consumo, São Paulo, v. 5, n. 14, p. 123-148, 2008. 
MARTINO, L. M. S. A religião midiatizada nas fronteiras entre o público e o privado.

Ciberlegenda, Niterói, v. 26, n. 1, p. 13-26, 2012b.

MARTINO, L. M. S. Mediação e Midiatização da Religião em suas articulações teóricas e práticas. In: MATTOS, M. A.; JACKS, N. (Org.). Mediações e midiatização. Salvador: Ed. UFBA, 2012. p. 219-244.

MARTINO, L. M. S. Teoria das mídias digitais. Petrópolis: Vozes, 2014.

MARTINO, L. M. S. The mediatization of religion. 2. ed. London: Routledge, 2016.

MARX, K. Grundrisse. São Paulo: Boitempo, 2015.

MATTOS, M. A.; JANOTTI, J.; JACKS, N. Mediações e midiatização. Salvador: Ed. UFBA, 2012.

MEITZ, T. G. K. Mediality: Aspects of contextual media reception. Empedocles: European Journal for the Philosophy of Communication, Bristol, v. 3, n. 2, p. 197-214, 2011.

MEYER, T. Media democracy. London: Polity, 2002.

MEYROWITZ, J. Images of media: hidden ferment - and harmony - in the field. Journal of Communication, Hoboken, v. 43, n. 3, p. 55-66, 1993.

MEYROWITZ, J. Medium theory. In: CROWLEY, D.; MITCHELL, D. Communication theory today. Stanford: Stanford University Press, 1994.

MEYROWITZ, J. No sense of place. Oxford: Oxford University Press, 1985.

MEYROWITZ, J. Understandings of media. Et Cetera, Fort Worth, v. 56, n. 1, p. 44-52, 1999.

PARES, D. A. Comunicação como midiatização: os meios em meio à tecnologia, sociedade, linguagem, e vice-versa. Em Questão, Porto Alegre, v. 14, n. 2, p. 247-259, 2008.

RAINIE, L.; WELLMAN, B. Networked: the new social operating system. Cambridge: MIT Press, 2012.

RÜDIGER, F. Os estudos de mídia e a problemática epistemológica da teoria da midiatização uma nova escolástica? Intexto, Porto Alegre, v. 34, n. 3, p. 745-769, 2015.

SANTAELLA, L. Linguagens líquidas na era da mobilidade. São Paulo: Paulus, 2007.

SCHOTT, A. Dimensions: catch-all label or technical term. In: In: LUNDBY, K. (Org.).

Mediatization: concept, changes, consequences. Nova York: Peter Lang, 2009. p. 41-62.

SCHULZ, W. Reconstructing mediatization as an analytical concept. European Journal of Communication, London, v. 19, n. 1, p. 87-101, 2004.

SGORLA, F. Discutindo o "processo de midiatização". Mediação, Belo Horizonte, v. 9, n. 8, p. 6068, 2009. 
SLACK, J. D. The theory and method of articulation in Cultural Studies. In: MORLEY, D.; KUANHSING, C. Stuart Hall: critical dialogues in cultural studies. Londres: Routledge, 1996.

SODRÉ, M. Antropológicas do espelho. Petrópolis: Vozes, 2004.

SOUSA, J. Teoria do meio. Brasília: Universa, 2009.

STRÖMBACK, J. Four phases of mediatization: an analysis of the mediatization of politics. International Journal of Press/Politics, Thousand Oaks, v. 13, n. 3, p. 228-246, 2008.

STRÖMBÄCK, J. Mediatization and perceptions of the media's political influence. Journalism Studies, Oxon, v. 12, n. 4, p.423-439, 2011.

THOMPSON, J. B. A mídia e a modernidade. Petrópolis: Vozes, 1998.

TURKLE, S. Alone together. New York: Basic Books, 2012

VERÓN, E. La mediatización. Buenos Aires: Editora da UBA, 1986.

VERÓN, E. La semiosis social 2. Buenos Aires: Paidós, 2013.

WEBER, M. Economia e sociedade. Brasília: Ed. UnB, 1991.

WELLMAN, B. Computer networks as social networks. Science, London, v. 293, p. 2031-2034, 2001.

ZENGOTITA, T. Mediated: how the media shape your world. London: Bloomsbury Publishing, 2005.

\title{
Towards a mediatization theory: a methodological exercise
}

\begin{abstract}
The concept of mediatization has been increasingly used in theCommunication studies at least since the last two decades. Although many authors have used the concept in different ways, there seems to be some common features that indicate what could be a concept of mediatization. Based on bibliographical research, this paper explores similar elements which seem to understandmediatization as (a) the articulation, not 'influence' or 'effects', between (b) the "media", understood as institution, technology and language and (c) social practices, understood as everyday actions embedded on a social context. The paper places
\end{abstract}


these common elements against the background of Communication Theory and Research.

\section{Keywords}

Mediatization. Social practice. Communication theory. Epistemology.

Recebido em 07/11/2017

Aceito em 17/02/2018 